\title{
Sensibilização, Território e Vulnerabilidades: Potências da Educação Popular em Saúde na Formação do Enfermeiro
}

\author{
Awareness, Territory and Vulnerabilities: Potentials \\ of Popular Health Education in the training of Nurses
}

\author{
Liciane da Silva Costa Dresch ${ }^{1}$ \\ Tanisa Lazarini ${ }^{1}$ \\ Cristianne Famer Rocha ${ }^{2}$
}

\section{RESUMO}

A formação em saúde constitui-se na implementação de diferentes possibilidades pedagógicas, inventivas e potentes na arte do ensinar-aprender. Para que o futuro trabalhador da saúde dialogue integralmente com o cuidado, é fundamental que este se sensibilize, lançando mão de dispositivos que possam (trans)formar suas vivências a partir de um "sensibilizar em saúde", essencial para a promoção do cuidado humanizado, ampliado nos diferentes contextos de realidade social. Este artigo objetivou relatar as atividades de educação popular desenvolvidas pelos discentes de um Curso de Enfermagem de uma instituição universitária do Sul do Brasil, a partir de suas inserções em territórios de vulnerabilidade e pobreza extrema, enquanto processo de sensibilização em saúde e promoção do cuidado integral. Trata-se de um relato de experiência de abordagem qualitativa, onde são relatadas as construções pedagógicas de um cuidado coletivo e sensível. A compreensão de como se dá a (des)construção do acadêmico de Enfermagem é fundamental, quando este se depara com construções sociais distintas de sua realidade, sobretudo quando se utiliza do protagonismo dos indivíduos. Sensibilzar-se, assim, implica rever conceitos e práticas, entrelaçado aos detalhes e características singulares dos territórios e das subjetividades de cada indivíduo envolvido no processo de cuidar.

\section{PALAVRAS-CHAVE}

Sensibilização; Território; Vulnerabilidade; Educação popular.

${ }^{1}$ Centro Universitário Metodista - IPA.

${ }^{2}$ Universidade Federal do Rio Grande do Sul. 


\section{ABSTRACT}

Health education is the implementation of different pedagogical possibilities, inventive and powerful in the art of teaching and learning. For the future health worker to dialogue fully with care, it is essential that the health worker sensitize himself, making use of devices that can (trans)form his experiences based on a "health awareness", essential for the promotion of humanized care, expanded in the different contexts of social reality. This article aimed to report on the popular education activities developed by the students of a Nursing Course at a university institution in Southern Brazil, from their insertions in territories of vulnerability and extreme poverty, as a process of health awareness and promotion of integral care. This is an experience report with a qualitative approach, where emotions related to sensitive. Understanding how the (under)construction of the nursing student takes place is fundamental when he/she faces social constructions distinct from their reality, especially when art can be the tool of expression, otherness and empathy. Sensitizing, thus, involves reviewing concepts and practices, intertwined with the unique details and characteristics of the territories and subjectivities of each individual involved in the care process.

\section{KEYWORDS}

Sensitization; Territory; Vulnerability; Popular education. 


\section{INTRODUÇÃO}

Na formação em saúde, é um desafio constante o uso de diferentes possibilidades pedagógicas, inventivas e potentes na arte do ensinar-aprender. Problematizar a realidade social no território e possibilitar processos educativos conectados à realidade cultural dos usuários torna-se, talvez, a incitação mais complexa para o trabalhador de saúde.

Para tanto, a prática voltada para a promoção, alinhada às necessidades do Sistema Único de Saúde (SUS) é chamada de Educação Popular em Saúde (EPS). Trata-se de uma Política Nacional, em vigor desde 2013, que valoriza os saberes populares e tem como objetivos o diálogo, a problematização e a construção compartilhada do conhecimento, em sintonia com a construção do projeto democrático e popular brasileiro (BRASIL, 2013). Outro conceito importante é aquele de Promoção em Saúde, também proposto a partir de uma Política Nacional (BRASIL, 2014). Atividades de Promoção da Saúde são mais amplas que as de prevenção, uma vez que a Promoção não se limita a uma determinada doença, pois seu objetivo é aumentar e melhorar a saúde. A promoção não apresenta ações focadas ou intervenções específicas para ter o controle do progresso de doenças, como a prevenção em saúde. Trata-se de um processo amplo e dialogado, construído entre os diferentes atores envolvidos no processo de cuidado (CZERESNIA; FREITAS, 2014).

Historicamente, as transformações do setor da saúde brasileiro, advindas das conquistas do movimento sanitário, levaram à reestruturação do sistema nacional de saúde, como também a geração de tensionamento nas instituições quanto à necessidade de políticas de formação profissional dos trabalhadores. Na década de 1980, os intensos movimentos em prol da descentralização dos serviços de saúde e da universalização do acesso demandaram desafios às forças políticas reunidas em torno da reforma sanitária. Era necessário o cumprimento das premissas da reforma, como a universalidade, a equidade e a integralidade da atenção à saúde (BARRETO JÚNIOR; SILVA, 2004).

Para Lima (2010), essa década, marcada pelo processo de democratização da sociedade brasileira e pelo processo constituinte, deu origem a matrizes de formação profissional em saúde no interior do setor público, tendo como discussão central a articulação entre trabalho, educação e saúde. Uma destas matrizes organizou-se em função da proposta da educação politécnica no interior da Fundação Oswaldo Cruz (Fiocruz), sediada no Rio de Janeiro (RJ), com atuação voltada para a formação de novos quadros para o campo da ciência e tecnologia, assim como para o novo sistema de saúde que estava sendo desenhado na época.

Sant'anna et al. (2008) descrevem que, após a institucionalização do SUS, foi necessário redesenhar as competências profissionais dos trabalhadores da saúde (conforme o conceito ampliado de saúde), que também se encontrava em pleno processo de reformulação, a partir das discussões propostas pelo Movimento da Reforma Sanitária. Ainda para os autores, a área de recursos humanos passou a ter mais visibilidade no setor saúde após a VIII Conferência Nacional de Saúde, que demandou a realização de conferências específicas sobre a questão dos recursos humanos em saúde (BRASIL, 1986a). Já no mesmo ano, 1986, foi realizada a I Primeira Conferência Nacional de Recursos Humanos para a Saúde (BRASIL, 1986b). Naquele momento, era premente, também, a discussão sobre a reorganização das práticas em saúde, assim como a mudança das suas bases jurídicas, visto o processo de implantação do SUS que, naquele momento, estava se desenhando.

Ceccim e Feuerwerker (2004) elaboraram uma transformadora proposta para os processos de organização dos serviços e formação dos trabalhadores do setor saúde, através de uma articulação entre as instituições formadoras, esferas de gestão e o sistema de saúde. Surge, então, a noção de Quadrilátero da Formação, que articula os segmentos da formação, da atenção, da gestão e do controle social em saúde na proposição de valorização das características locais, capacidades instaladas e desenvolvimento das potencialidades existentes em cada realidade. Estabelece, também, processos de aprendizagem críticos e significativos, além da autogestão, autoanálise e produção de sentidos. Segundo Costa e colaboradores (2014), esta proposta coloca em evidência a formação para a área da saúde como construção da educação em serviço/ educação permanente em saúde, agregando o desenvolvimento individual e institucional, os serviços, a atenção à saúde e o controle social. 
Neste cenário, as políticas para a educação profissional em saúde são construídas de forma gradativa, em um cenário de contradições internas existentes nos aparelhos do estado, e não mostraram-se totalmente suficientes para formar trabalhadores que pudessem superar o modelo curativo e biologicista de atenção à saúde, pois este também é fruto de um modelo de sociedade. Ciavatta e Ramos (2012) analisam que o desafio que a educação contemporânea no Brasil é superar este modelo, seguindo tendências internacionais, no sentido de formar personalidades flexíveis para a adaptação à realidade instável e incerta.

Assim, para que o futuro trabalhador da saúde dialogue integralmente com as diretrizes da Promoção da Saúde e da Educação Popular em Saúde é fundamental que este se sensibilize, lançando mão de dispositivos que possam (trans)formar suas vivências a partir de um “sensibilizar em saúde",essencial para a promoção do cuidado humanizado, integral e ampliado nos diferentes contextos de saúde e de realidade social. Neste relato de experiência docente, as práticas desensibilização em saúde, segundo Costa, Normann e Cicolella (2018) traduzem-se como um conjunto de dispositivos capazes de promover alteridade e empatia, despertadas a partir das artes, da poesia, dos encontros e seus afetos, e que promovem diferentes leituras da realidade. Desta forma, promover o cuidado em contextos de vulnerabilidade social necessita de uma nova lente, de um olhar ampliado disposto a tecer pluralidades entre trabalhadores da saúde e usuários.

Ao longo dos semestres e nos diferentes campos de prática dos estágios de um Curso de Enfermagem de uma instituição universitária do Sul do Brasil propiciou-se a construção de momentos pedagógicos que oportunizaram a reflexão e encontros com diferentes contextos de realidade social. A problematização acercadas principais dificuldades que o trabalho em equipe encontra junto aos territórios de vulnerabilidade social proporciona estratégias diferenciadas de ensino e de cuidado, fundamentais para a formação do enfermeiro.

As vivências nos estágios, a partir de reflexões acerca do cuidado e da alteridade atuaram enquanto propulssoras de uma inserção sensível e colaborativa na perspectiva da Educação Popular em Saúde. Para Linhares (2003), esta é uma prática voltada para a promoção, a proteção e a recuperação da saúde a partir do diálogo entre a diversidade de saberes, valorizando os saberes populares, a ancestralidade, a produção de conhecimentos e a inserção destes no SUS. São necessários encontros dentro e fora da sala de aula, em espaços de diálogo que permitam a "desacomodação" pedagógica.

Antes da inserção na prática em campo, tornou-se fundamental um questionamento: o que os acadêmicos do quarto e quinto semestres do Curso de Enfermagem sabemsobre vivernestaslocalidades? Quaisosobstáculos e potencialidades em se "construir saúde" a partir dos saberes populares? Para esta escrita, escolheu-se uma atividade de Educação Popular em Saúde originada a partir de um processo de reconhecimento sensível do território junto aos seus moradores.

\section{METODOLOGIA}

Trata-se de um relato de experiência de abordagem qualitativa, onde são relatadas as emoções acerca do cuidar sensível. Objetivou-se relatar as atividades de educação popular desenvolvidas pelos discentes de um Curso de Enfermagem de uma instituição universitária do Sul do Brasil.

O percurso de sensibilização em saúde e promoção do cuidado integral, junto aestágios na área de Atenção Primária em Saúde, ocorreu no período de 2015 a 2017, com discentes do quinto e oitavo semestres do Curso de Enfermagem, em disciplinas sobre Saúde Coletiva, em um território de vulnerabilidade social.

Os dados foram produzidos a partir da elaboração de diários de campo sobre as atividades de Educação Popular em Saúde. 0 diário de campo consiste em um instrumento capaz de possibilitar o exercício acadêmico na busca da identidade profissional à medida que, através de aproximações sucessivas e críticas, pode-se realizar uma reflexão da ação profissional cotidiana, sendo uma fonte inesgotável de construção e reconstrução do conhecimento profissional e do agir de registros qualitativos (LEWGOY: ARRUDA, 2004)

Em relação às considerações éticas, a pesquisa seguiu o quanto previsto na Resolução 510/2016 (BRASIL, 2016), considerando as especificidades das Ciências Humanas e Sociais e, em conformidade com o Art. 1ํㅡㄹ parágrafo único, pesquisas que envolvam 
"atividade realizada com o intuito exclusivamente de educação, ensino ou treinamento sem finalidade de pesquisa científica, de alunos de graduação, de curso técnico, ou de profissionais em especialização (...) não serão registradas nem avaliadas pelo sistema CEP/ CONEP [Comitê de Ética em Pesquisa do Conselho Nacional de Pesquisa]".

\section{RESULTADOS E DISCUSSÕES}

A inserção das práticas de estágio ocorreu em uma Unidade de Saúde da Família (USF) localizada em um município do Sul do Brasil, cujo território é marcado por vulnerabilidades sociais e violência, comuns em espaços mais periféricos dos grandes centros urbanos A partir do mapeamento do território, deparou-se com um espaço mais distante, invisível àqueles que circulam pelas ruas e avenidas principais da entrada da cidade. Acolhidos em um espaço compreendido entre a beira de um rio e a estreita vegetação que acompanha uma autoestrada, vive uma comunidade que iniciou a ocupação do terreno em meados dos anos 1970 e que abriga em torno de 48 famílias. Até então vista pelas diferentes equipes de saúde como uma comunidade de difícil vínculo, esta informação instigou o grupo de estágio para a compreensão da realidade local. Tornouse, então, um desafio compreender a possível composição de cuidado junto a esta comunidade,em uma perspectiva da Educação Popular em Saúde.

A inclusão do grupo deu-se de forma gradual, uma vez que não havia informações prévias relativas ao território e suas características. A primeira visita local ocorreu com a Agente Comunitária de Saúde da USF, responsável pelo acompanhamento daquelas famílias. O grupo foi apresentado ao líder comunitário local, surpreso com a presença dos acadêmicos e o interesse pela saúde dos moradores daquela comunidade.

Não havia histórico prévio de um processo coletivo de Educação em Saúde naquela comunidade. A partir desta perspectiva, foram convidados todos os moradores para uma roda de conversa, cujo convite era: "O que tu, morador desse local, espera para tua vida? Para tua saúde?Como é viver aqui?Quais as relações de cuidado e decura que existem aqui? Conte-nos suas experiências sobre estas questões, queremos aprender com vocês".

A roda de conversa foi longa e participativa. Muitas narrativas, momentos de silêncio e desabafos. Os assuntos debatidos centraram-se na busca por condições dignas de moradia, de saneamento, passando pelo adoecimento psicológico gerado pelas privações (de dinheiro, de recursos alimentares, de emprego formal). Em relação ao tema Saúde, foi pontuado que a coletividade e os saberes populares utilizados naquela comunidade (uso de chás, benzeduras) somavam-se ao cuidado formal dispensado pelas equipes da Unidade de Saúde da Família.

Sem dúvida, o ponto mais importante dessa conversa foi à percepção de que este grupo de pessoas buscava espaços coletivos junto à comunidade para ficarem com uma "cabeça boa": trouxeram o desejo de uma brinquedoteca e de um espaço de convivência para crianças e idosos, dentro do território, para que pudessem permanecer mais tempo unidos, aprendendo uns com os outros. Esse momento foi crucial para a reflexão do protagonismo destes indivíduos em seu processo de cuidado.

Para que pudessem ressignificar seus saberes sobre saúde física e mental e cuidado de si, entendiam que o essencial era um espaço físico que abrigasse e potencializasse estas propostas. Esta comunidade queria existir no coletivo, na potência de seus saberes sobre saúde e cuidado, em um espaço que abrigasse sua pluralidade e a troca de saberes que circulavam entre eles. Os acadêmicos e docentes puderam compreender, neste espaço da escuta, um dos possíveise potentes significados de Educação Popular em Saúde e, a partir de então, o grupo começou a traçar algumas estratégias coletivas para este fim. 
Foto 1. Território, casa, futura sede da Brinquedoteca.

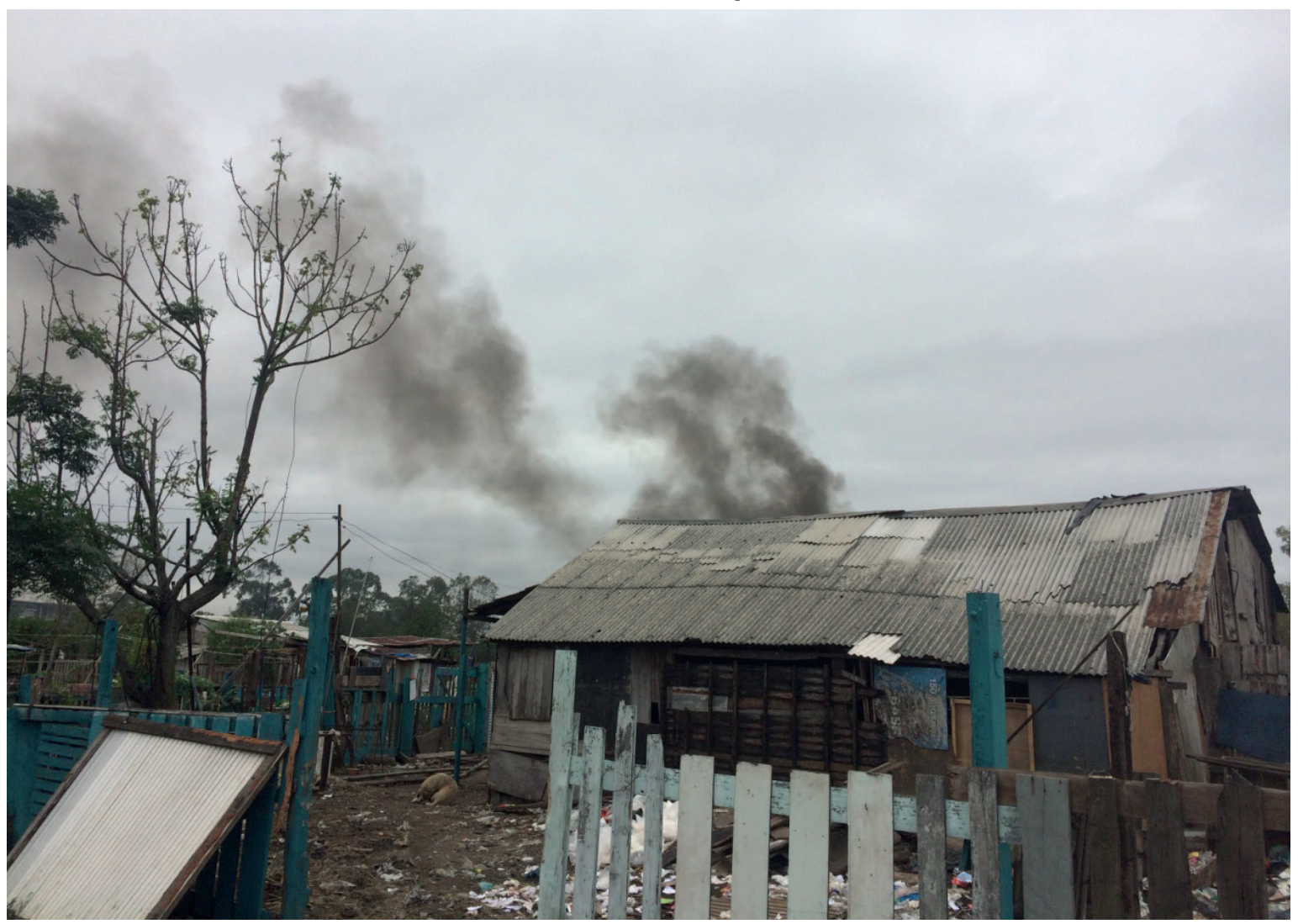

Fonte: acervo pessoal das pesquisadoras.

A partir de doações externas e buscas por materiais recicláveis no próprio território, iniciou-se a construção coletiva da Brinquedoteca. Cada morador foi fundamental e singular neste processo. Este espaço, chamado por alguns de "Brinquedoteca da Beira do Rio", existe até os dias atuais e recicla-se periodicamente a partir das iniciativas dos acadêmicos, da equipe da USF e de uma ONG de inclusão social do município.

Houve doação de materiais solicitados pela comunidade: gibis, revistas, um pôster do corpo humano, um mural de fotos, sobretudo das crianças e dos núcleos familiares que ali residem. Somado a isso, construiu-se coletivamente cartazes com informações em saúde propostos por muitos deles: tratamento de tuberculose, infecções sexualmente transmissíveis, uso de anticoncepcionais e preservativos, utilização de chás e receitas elaboradas pelas mulheres idosas da comunidade. Com esta experiência, presenciou-se a construção depotências devida, resgates deidentidades, empoderamento de saberes, a partir da Promoção da Saúde acontecendo em ato, harmoniosamente compostos e tecidos a partir da realidade local e do protagonismo ativo dos seus atores.

Reflete-se, a partir desta experiência, que o desafio atual da formação em saúde é, sobretudo, a conexão do acadêmico junto à realidade cultural e social dos diferentesterritóriose,comodecorrênciadessaaproximação física, sua compreensão e aprendizado propiciados. Para Adorno (2008), torna-se fundamental pensarmos as especificidades relativas à diversidade de grupos sociais e das suas condições históricas de vida e problemas de saúde a que estão expostos. É necessário, assim, lançarmos mãos dos conhecimentos da Antropologia e das Ciências Sociais, além daquelas relativas às Artes e outras áreas de saberes, para uma compreensão mais apurada de nossas estratégias no campo da saúde, em especial nos processos de cuidado junto às vulnerabilidades.

Os diferentes momentos do estágio no território originaram alguns produtos criados pelos acadêmicos: a criação de um vídeo e fotos que foram divulgadas e expostas em diferentes espaços de circulação da instituição universitária, como convite para pensarmos, interprofissionalmente, a Educação Popular em Saúde. 
Foto 2. Construção coletiva da Brinquedoteca.

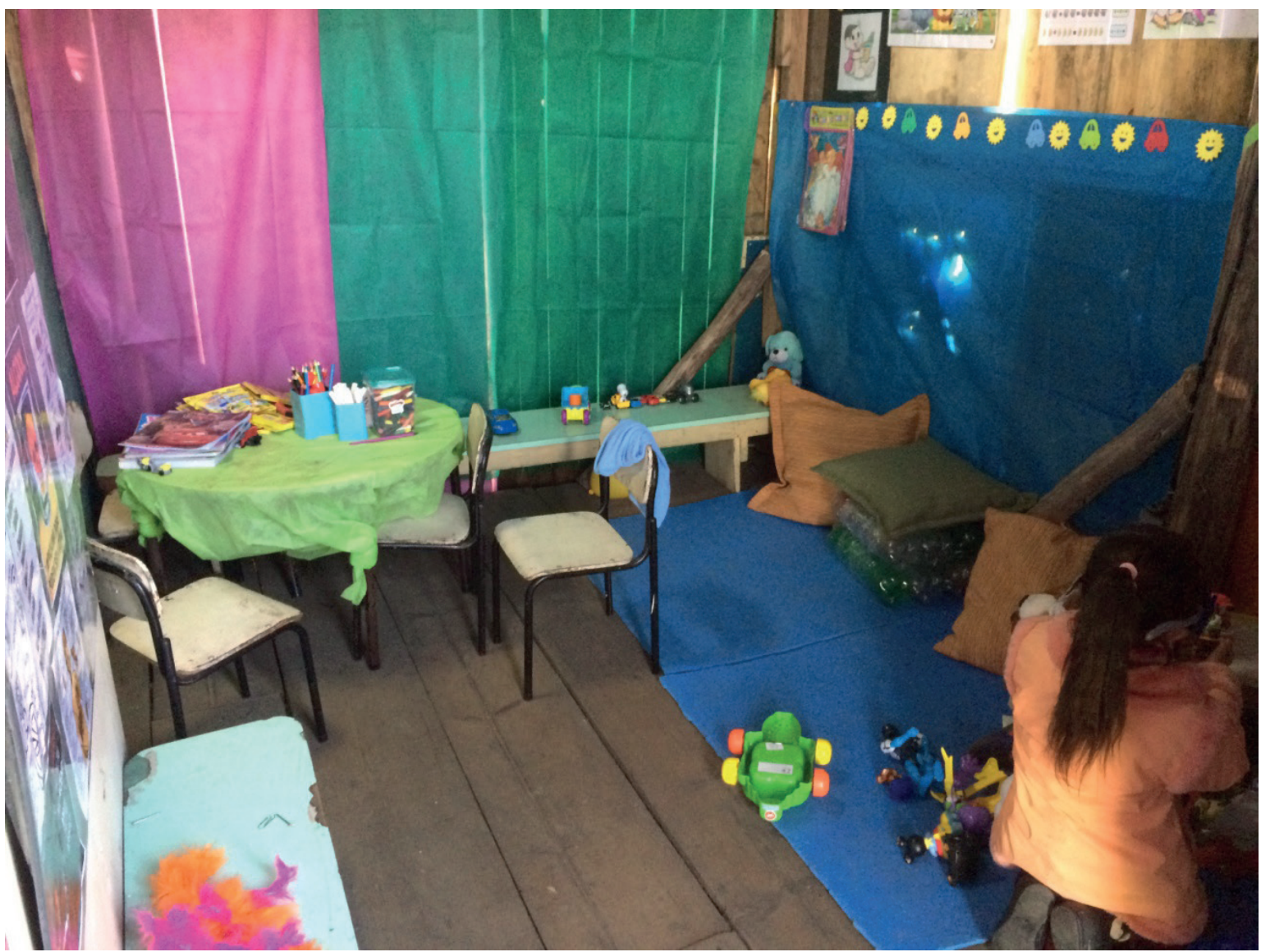

Fonte: acervo pessoal das pesquisadoras.

\section{CONSIDERAÇÕES FINAIS}

O ensino de saúde tecnicista, biomedicalizante e exclusivamente curativo não possibilita ao educando a visualização dos determinantes sócio-culturais no processo de saúde-doença.

A educação (trans)formadora precisa contextualizar as realidades, demonstrar as vulnerabilidades e propor alternativas de construção de melhores práticas baseadas nas emoções e no cuidado humanizado.

0 ensino em uma abordagem contextualizada deveria englobar a educação, a saúde, a psicologia, a sociologia, enfim, todos os saberes que reforçam nos indivíduos a complexidade da vida, suas (im)possibilidades de escolhas e a compreensão do quanto a saúde depende de inúmeros fatores e determinantes. Por isto, a formação profissional deve estar voltada para ações integrais e integradoras, inclusivas, participativas, pois sem elas o foco serão as ações prescritivas de prevenção e o controle de doenças, sem que se considere de maneira mais ampla a produção da saúde, em contextos complexos e difíceis como este onde foi realizado o exercício formativo

A educação tem por objetivo formar profissionais para trabalhar no campo da saúde, em todas as suas dimensões, e esse desafio se torna maior na medida em que precisamos, muitas vezes, desconstruir práticas normalizadas e naturalizadas, social e culturalmente. Desconstruir significa repensar, refazer, mas não a partir do mesmo e sim a partir do novo, incluindo o ambiente local e global e incorporando elementos sócio-culturais nessa nova construção e, a partir daí, buscar promover a saúde em todas as suas dimensões e através de todas as estratégias educativas que temos à disposição.

Quando a dimensão político-econômico-social da saúde é desconsiderada no cenário, processo de 
formação fica mais fácil desconsiderar a saúde como um direito e retirar daspessoas a capacidade reivindicatória, possibilitando a aceitação de serviços excludentes e privativos como sendo direito de apenas alguns (os que "merecem" viver em melhores condições).

Nesse sentido, considera-se importante, no processo acadêmico de formação, vincular a prática aos saberes da própria vida desses indivíduos (moradores). Essa tarefa exige, principalmente, um olhar atento e cuidadoso às vulnerabilidades e os direitos humanos, pois é a partir dele que será possível promover a ampliação das experiências educadoras alinhadas aos desafios acadêmicos. Entende-se, assim, que os espaços acadêmicos dentro e fora das universidades devam potencializar sua responsabilidade social. 


\section{REFERÊNCIAS}

ADORNO, R. C.; VASCONCELLOS, M. P. C.; ALVARENGA, A. T. Saúde Pública, Ciências Sociais e as chamadas populaçõesvulneráveis. In: ROCHA, Aristides Almeida e CESAR, Chester Luiz Galvão. Saúde Pública: Basesconceituais. São Paulo: Atheneu, 2008, p. 297-310.

BARRETO JUNIOR, I. F.; SILVA, Z. P. Reforma do Sistema de Saúde e as novas atribuições do gestor estadual. São Paulo em Perspectiva, São Paulo, v. 18, n. 3, p. 47-56, jul./set. 2004.

BRASIL. Conselho Nacional de Saúde. Resolução 510, de 7 de abril, de 2016. Brasília: Ministério da Saúde, 2016.

BRASIL. Ministério da Saúde. Portaria no 2.761, de 19 de Novembro de 2013. Política Nacional de Educação Popular em Saúde no âmbito do Sistema Único de Saúde (PNEPS-SUS). Brasília, Ministério da Saúde, 2013.

BRASIL. Ministério da Saúde. Secretaria de Gestão Estratégica e Participativa. II Caderno de Educação Popular em Saúde. Brasília: Ministério da Saúde, 2014.

BRASIL. Ministério da Saúde. Secretaria Geral de Recursos Humanos. Conferência Nacional de Recursos Humanos: Relatório Final. Brasília: Ministério da Saúde, 1986.

BRASIL. Conselho Nacional de Saúde. Relatório da VIII Conferência Nacional de Saúde. Brasília: Ministério da Saúde, 1986.

CECCIM, R.B.; FEUERWERKER L.C.M. O quadrilátero da formação para a área da saúde: ensino, gestão, atenção e controle social. Physis, Rio de Janerio, v.14,no 1, p.41-65, 2004.

CIAVATTA, M.; RAMOS, M. A "era das diretrizes": a disputa pelo projeto de educação dos mais pobres. RevistaBrasileira de Educação, Rio de Janeiro, v. 17, n.49, jan-abr 2012.
COSTA, M.V.; VILAR, M.J.; AZEVEDO, G.D.; REEVES, S. Interprofessional education as an approach for reforming health professions education in Brazil:emerging findings. J InterprofCare. 2014 Jul;28(4):379-80. http://dx.doi.org/10.3 109/13561820.2013.870984. PMid:24383408.

COSTA, L.S. NORMANN,K.S, CICOLLELA, D.A. O sensibilizar em saúde: arte e cultura no contexto de formação do enfermeiro. In: NORMANN,K.S. ET al. Metodologias ativas. Porto Alegre: Editora Universitária Metodista, 2018.

CZERESNIA, Dina. O conceito de saúde e a diferença entre prevenção e promoção. In: CZERESNIA, Dina \& FREITAS, Carlos Machado. Promoção da saúde: conceitos, reflexões, tendências. Rio de Janeiro: FIOCRUZ, 2014, p. 39-53.

LEWGOY, Alzira Ma. B; ARRUDA, Maria P. Novas tecnologias na prática profissional do professor universitário: a experimentação do diário digital. Revista Texto \& Contextos, Porto Alegre, n.2, p.115-130, 2004.

LIMA, J.C.D. Política de saúde e formação profissional dos trabalhadores Técnicos de Enfermagem. Tese (Doutorado em Políticas Públicas e Formação Humana). Faculdade de Educação, Universidade do Estado do Rio de Janeiro, Rio de Janeiro, 2010.

LINHARES, Ângela Maria Bessa. 0 tortuoso e doce caminho da sensibilidade: um estudo sobre arte e educação. Ijuí: Unijuí, 2003.

PORTO ALEGRE. Secretaria Municipal de Saúde. Plano Municipal de Saúde 2018-2021. Porto Alegre, 2017.

SANT'ANNA et al. A influência das políticas de educação e saúde nos currículos dos cursos de educação profissional técnica de nível médio em enfermagem. Trab. Educ. Saúde, v. 5 n. 3, p. 415-431, nov. 2007/fev. 2008. 